\title{
LES RÉACTEURS NUCLÉAIRES DE RECHERCHE EN FRANCE
}

$D$ ans le domaine des réacteurs nucléaires destinés à la recherche fondamentale ou appliquée, la France dispose d'un équipement aux très larges possibilités.

Cet équipement est un facteur indispensable à la maîtrise de la science et des techniques nucléaires. Il s'avère notamment très précieux pour la conduite du développement à grande échelle du programme électronucléaire.

Précieux mais mal connu - partageant d'ailleurs ce douteux privilège avec les autres installations ou équipements ne débouchant pas sur des utilisations pratiques immédiates.

A quoi servent les réacteurs de recherche? Quels objectifs leur sont-ils assignés? Comment sont-ils utilisés? Quelles perspectives s'ouvrent à leurs investigations?

Le dossier que nous présentons apporte à ces questions quelques éléments de réponse.

Nous adressons nos plus vifs remerciements à tous ceux qui ont bien voulu contribuer à sa réalisation.

Nos remerciements vont aussi à M. Yves Sousselier qui a assuré la coordination de l'ensemble.

F. S. 